\title{
The impact of chronic intermittent hypoxia on hematopoiesis and the bone marrow microenvironment
}

\author{
Inês Alvarez-Martins ${ }^{1,2}$ • Leonor Remédio ${ }^{1}$ • Inês Matias ${ }^{1,2}$ • Lucília N. Diogo ${ }^{3,4}$ • \\ Emília C. Monteiro ${ }^{3,4}$ - Sérgio Dias ${ }^{2}$
}

Received: 9 November 2015 / Revised: 21 December 2015 / Accepted: 26 January 2016 / Published online: 9 February 2016

(C) The Author(s) 2016. This article is published with open access at Springerlink.com

\begin{abstract}
Obstructive sleep apnea (OSA) is a highly prevalent sleep-related breathing disorder which is associated with patient morbidity and an elevated risk of developing hypertension and cardiovascular diseases. There is ample evidence for the involvement of bone marrow (BM) cells in the pathophysiology of cardiovascular diseases but a connection between OSA and modulation of the BM microenvironment had not been established. Here, we studied how chronic intermittent hypoxia $(\mathrm{CIH})$ affected hematopoiesis and the $\mathrm{BM}$ microenvironment, in a rat model of OSA. We show that $\mathrm{CIH}$ followed by normoxia increases the bone marrow hypoxic area, increases the number of multipotent hematopoietic progenitors (CFU assay), promotes erythropoiesis, and increases monocyte counts. In the BM microenvironment of CIH-subjected animals, the number of VE-cadherinexpressing blood vessels, particularly sinusoids, increased, accompanied by increased smooth muscle cell coverage,
\end{abstract}

Inês Alvarez-Martins and Leonor Remédio contributed equally to this work.

Electronic supplementary material The online version of this article (doi:10.1007/s00424-016-1797-6) contains supplementary material, which is available to authorized users.

Sérgio Dias

sergiodias@medicina.ulisboa.pt

1 Angiogenesis Lab, CIPM, Portuguese Institute of Oncology, IPOLFG, EPE, Lisbon, Portugal

2 Instituto de Medicina Molecular, Edificio Egas Moniz, Faculdade de Medicina da Universidade de Lisboa, 1649-028 Lisbon, Portugal

3 CEDOC, Nova Medical School, Universidade Nova de Lisboa, Campo dos Mártires da Pátria, 130, 1169-056 Lisbon, Portugal

4 Translational Pharmacology Lab, Universidade Nova de Lisboa, Campo dos Mártires da Pátria, 130, 1169-056 Lisbon, Portugal while vWF-positive vessels decreased. Molecularly, we investigated the expression of endothelial cell-derived genes (angiocrine factors) that could explain the cellular phenotypes. Accordingly, we observed an increase in colony-stimulating factor 1, vascular endothelium growth factor, delta-like 4, and angiopoietin-1 expression. Our data shows that $\mathrm{CIH}$ induces vascular remodeling in the $\mathrm{BM}$ microenvironment, which modulates hematopoiesis, increasing erythropoiesis, and circulating monocytes. Our study reveals for the first time the effect of $\mathrm{CIH}$ in hematopoiesis and suggests that hematopoietic changes may occur in OSA patients.

Keywords Chronic intermittent hypoxia $\cdot$ Hematopoiesis . Vascular niche $\cdot$ Bone marrow microenvironment

\section{Introduction}

Hematopoiesis has long been known to be affected by environmental hypoxia [64]. Despite numerous reports relating hypoxia with hematopoietic modulation $[3,5,44,46,48,49$, $61,64]$ and the great attention currently given to hypoxiainducible factor (HIF) [34], the current scientific knowledge largely relies on of studies performed under acute hypoxia stimulation in isolated systems. Therefore, the role of chronic systemic hypoxia in the bone marrow (BM) microenvironment and hematopoiesis is still unknown.

Here, we studied the role of environmental hypoxia using a clinically relevant chronic intermittent hypoxia $(\mathrm{CIH})$ model, which consists of exposing the experimental animals to a paradigm of $\mathrm{CIH}$ for 30-35 days, as a model of obstructive sleep apnea syndrome (OSA) [25]. OSA is an increasingly prevalent condition affecting children and adults, which is renowned as a frequent secondary cause of hypertension [16]. There is ample evidence for the involvement of BM-derived 
cells in the pathophysiology of hypertension [78] but a relation between OSA and modulation of the BM microenvironment had not been shown and is the subject of the present study. The clinical hematological aspects of OSA are still largely unknown, with several studies reporting mainly platelet activation and increased hematocrit, but not assessing BM or circulating blood cell alterations [22]. Furthermore, these studies typically compared groups of patients with differing disease phenotypes [32] or treated versus untreated patients [42] but not healthy controls versus patients and do not explore the mechanisms involved [22].

Mechanistically, we focused on the vascular compartment of the BM, because it mediates the differentiation and proliferation of hematopoietic cells, as well as their egress from the BM microenvironment [40]. Furthermore, one of the most striking effects of hypoxia is the promotion of angiogenesis, which results from hypoxia inducible factor (HIF)-mediated increase in vascular endothelial growth factor (VEGF) expression [62].

The causal relationship between intermittent hypoxia and increased VEGF expression is known in both OSA patients [43] and healthy volunteers [7], but the relevance of this finding is still unknown.

The present work aims to explore for the first time whether $\mathrm{CIH}$ induce changes in the BM vascular compartment, which might in turn modulate hematopoiesis.

Our data suggests that $\mathrm{CIH}$ may promote erythropoiesis, increase the multipotential progenitor cell-derived CFUs accompanied by an increase in BM myeloid and B lymphocyte counts and a decrease BM T cells. Additionally, CIH also induces expansion of the blood monocyte compartment and perturbs the BM microenvironment by interfering with the vascular niche. Together, our results reveal hematopoietic and hematological complications of $\mathrm{CIH}$ which need to be validated and evaluated in a clinical setting.

\section{Methods}

\section{Animals}

Experiments were performed in twelve (12) male Wistar rats, aged 8-12 weeks, obtained from the NOVA Medical School animal facility. Animals were housed in polycarbonate cages, under 12-h light/dark cycles ( $8 \mathrm{am}-8 \mathrm{pm})$ at a room temperature $22 \pm 2.0{ }^{\circ} \mathrm{C}$ and relative humidity $60 \pm 10 \%$. Rats were maintained one or two per cage with ad libitum access to food and water. Applicable institutional and governmental regulations concerning ethical use of animals were followed, according to the NIH Principles of Laboratory Animal Care (NIH Publication 85-23, revised 1985), the European guidelines for the protection of animals used for scientific purposes (European Union Directive 2010/63/EU), and the
Portuguese Law $n^{\circ} 113 / 2013$. Experimental procedures were previously approved (nr. 21/2013/CEFCM) by the Institutional Ethics Committee of the NOVA Medical School for animal care and use in research.

\section{In vivo experiments}

Rats were divided into two groups: normoxia and $\mathrm{CIH}$. Animals were kept in a eucapnic atmosphere, inside of medium A-chambers $(76 \times 51 \times 51 \mathrm{~cm}, \mathrm{~A}-60274-\mathrm{P}$, Biospherix Ltd, NY, USA) with ad libitum food and water access. The chambers were equipped with gas injectors and sensors for oxygen $\left(\mathrm{O}_{2}\right)$ and carbon dioxide $\left(\mathrm{CO}_{2}\right)$ levels in order to ensure the accuracy of $\mathrm{CIH}$ cycles. Accumulation of $\mathrm{CO}_{2}$ was prevented by the continuous flow of the gas mixtures through vent holes and the presence in the chamber of self-indicating soda lime, which absorbs the expired $\mathrm{CO}_{2}$. The $\mathrm{CO}_{2}$ levels inside the chambers never exceeded $1 \%$. A silica gel container was also placed inside the chambers in order to absorb water. Oxygen concentration inside the chambers was controlled using $100 \%$ nitrogen $\left(\mathrm{N}_{2}\right)$ and $100 \% \mathrm{O}_{2}$ by an electronically regulated solenoid switches in a three-channel gas mixer, which gradually lowered oxygen in the chamber from 21 to $5 \% \mathrm{O}_{2}$ (OxyCycler AT series, Biospherix Ltd, NY, USA). The chambers were infused with $100 \% \mathrm{~N}_{2}$ for $3.5 \mathrm{~min}$ to briefly reduce the $\mathrm{O}_{2}$ concentration to $5 \%$ and then with $100 \% \mathrm{O}_{2}$ for $7 \mathrm{~min}$ to restore oxygen to ambient levels of $21 \%$, until the start of the next $\mathrm{CIH}$ cycle. Each $\mathrm{CIH}$ cycle lasted $10.5 \mathrm{~min}$, and rats were exposed during their sleep period (light phase of light/ dark cycle) to $5.6 \mathrm{CIH}$ cycles/h, $10.5 \mathrm{~h} /$ day for 32 days and analyzed 3 days after the hypoxic period. During the remaining hours of the day, the chambers were ventilated with a constant flow of room air to keep oxygen levels at $21 \%$. $\mathrm{O}_{2}$ was purchased as regular gas bottles (Gasin, Portugal), while $\mathrm{N}_{2}$ was generated from the air by pressure swing adsorption technology using a high-output nitrogen generator (Nitrogen 15 Plus, PSA Technology, Sysadvance, Maia, Portugal).

\section{Sample collection}

After exposing rats to 32 days of hypoxia followed by 3 days in normoxia, rats were sacrificed by intraperitoneal injection with medetomidine $\left(0.5 \mathrm{mg} / \mathrm{kg}\right.$ body weight, Domitor ${ }^{\circledR}$, Pfizer Animal Health) and ketamine $(75 \mathrm{mg} / \mathrm{kg}$ body weight, Imalgene $1000^{\circledR}$, Mérial, Lyon, France), and cardiac puncture was performed to collect peripheral blood. Blood was collected in EDTA-coated tubes (Multivette 600, Sarstedt), and plasma sampling and complete blood counts were performed. Femur BM cells were flushed out with PBS $2 \%$ FBS, and the total BM cell count was assessed using a Burker hemocytometer (Blau Brand). 


\section{Hypoxia quantification in bone marrow sections}

Three days after the hypoxic period, the subjects were intravenously injected (via tail vein) with $60-\mathrm{mg} / \mathrm{kg}$ pimonidazole hydrochloride (Hypoxyprobe, Inc, Burlington, USA), a misonidazole-based compound, which forms adducts with thiol groups of proteins, peptides, and amino acids specifically in hypoxic cells $\left(\mathrm{pO}_{2}<10 \mathrm{mmHg}\right)$ (81). Two hours later, rats were euthanized using $60-\mathrm{mg} / \mathrm{kg}$ sodium pentobarbital IV (Eutasil, Ceva Santé Animale, Libourne, France) and transcardially perfused with PBS. Quantification of BM hypoxic areas was performed using the ImageJ software in 10 high-power fields ( $\times 400$ magnification) per animal.

\section{Flow cytometry}

Bone marrow and peripheral blood cells were treated with red blood cell lysis buffer (Biolegend) for $15 \mathrm{~min}$ in the dark and were then stained for anti-CD90 (HIS51) fluorescein isothiocyanate (FITC), anti-CD11b (WT.5) allophycocyanin (APC) (BD Biosciences), anti-CD117 (2B8) APC, anti-CD19 (1D3) PE-cyanine 7 (PE/Cy7) (eBiosciences), and anti-CD3 (17A2) APC-cyanine 7 (APC/Cy7) (BioLegend). Flow cytometric analyses were carried out using an LSR Fortessa flow cytometer equipped with FACS Diva 6.2 Software (BD Biosciences). Data were analyzed with a FlowJo 9.8.2 software.

\section{In vitro colony forming assay}

Femur BM cells were flushed with PBS 2 mM EDTA, treated with red blood cell lysis buffer (Biolegend) for $15 \mathrm{~min}$ in the dark and plated onto petri dishes for $2 \mathrm{~h}$. Non-adherent cells $\left(10^{5}\right.$ cells $)$ were collected and plated onto a semi-solid cytokine-supplemented methylcellulose medium (MethoCult GF M3434) (Stemcell Technologies). Each colony formed in this semi-solid medium is single-cell derived and represents the identity of the original progenitor cell $[6,15]$. The resulting colonies were scored after 1-2 weeks of culture, according to manufacturer's instructions.

\section{Immunostaining and imaging}

Femurs were formalin-fixed, decalcified with formic acid for 3 days, and processed for routine histopathology. Immunohistochemistry staining was performed on $3-\mu \mathrm{m}$ slices. Sections were treated for antigen retrieval and incubated with the primary antibodies listed in Table 1 for $1 \mathrm{~h}$ at room temperature, immunostained according to the visualization system manufacturer's instructions and counterstained with hematoxylin. The slides were then analyzed using a Leica DM2500 microscope, and all images were acquired with the $40 \times$ objective. The number of vessels or cells stained by each marker was quantified as a mean of 10 representative images of individual rat femurs. Sections for immunofluorescence were incubated with VE-cadherin for $1 \mathrm{~h}$ at room temperature followed by an incubation with an Alexa Fluor 488 secondary antibody (Life Technologies). DNA was stained with DAPI Vectashield mounting medium (H-1200, Vector Laboratories). Imaging was performed using a Zeiss LSM 510 META microscope, and images were acquired with the $40 \times$ water immersion objective.

\section{RNA isolation and quantitative PCR}

Bone marrow cells were collected by flushing off tibias with PBS $2 \%$ FBS. Cells were centrifuged at $1200 \mathrm{rpm}$ for $5 \mathrm{~min}$, collected to TRIzol Reagent (Invitrogen), and RNA was extracted according to manufacturer's instructions. Reverse transcription was performed with SuperScript II (Invitrogen), according to the manufacturer's protocol. Quantitative PCR was performed with Power SYBR Green PCR Master Mix (Roche) on a ViiA ${ }^{\mathrm{TM}} 7$ Real-Time PCR System (Life Technologies). The sequences of the oligonucleotides used are included in Table 2. A primer concentration of $180 \mathrm{nM}$ was found to be optimal in all cases. Amplification of hypoxanthine guanine phosphoribosyl transferase ( $\mathrm{Hprt}$ ) was used for sample normalization.

\section{Statistical analysis}

Results are expressed as mean \pm standard deviation. Data were analyzed using unpaired two-tailed student's $t$ test. $P$ values of $<0.05$ were considered statistically significant.

\section{Results}

\section{Chronic intermittent hypoxia does not affect BM cell number but modulates/perturbs hematopoiesis}

In this study, six male Wistar rats were exposed to chronic intermittent hypoxia for 32 days and then left in normoxia for three more days. The post-hypoxic period before the analysis allowed us to observe the persistent changes in hematopoiesis and the BM microenvironment. Notably, as assessed by hypoxyprobe staining, the extent of BM hypoxia was increased in $\mathrm{CIH}$ exposed animals (Fig. 1a, b), which was accompanied by an upregulation in Hifla messenger RNA (mRNA) (Fig. 1c), CIH was also associated with a significant decrease in whole body weight (Fig. 1d), an observation that had already been associated with both sustained and intermittent hypoxia exposure $[45,76]$. Nevertheless, concerning the $\mathrm{BM}$ cellular content (corrected to the total body weight of the animals), there was no alteration in the total number of BM cells caused by $\mathrm{CIH}$ (Fig. 1e). However, the percentage of 
Table 1 Primary antibodies used for immunohistochemistry

\begin{tabular}{llll}
\hline Antigen & Antigen retrieval & Dilution & Brand \\
\hline CD105 (Endoglin) & HIER, Tris-EDTA pH 9 & $1: 150$ & R\&D AF1320 \\
CD11b & HIER, Tris-EDTA pH 9 & $1: 100$ & BD 550282 \\
SMA & HIER, Tris-EDTA pH 9 & $1: 500$ & DAKO HHF35 \\
VE-cadherin & PIER, Pepsin & $1: 150$ & R\&D AF1002 \\
vWF & PIER, Pepsin & $1: 300$ & DAKO A0082 \\
Anti-goat, peroxidase & & ready-to-use & VectorLabs MP-7405 \\
Anti-mouse, peroxidase & & ready-to-use & DAKO K4007 \\
Anti-rabbit, peroxidase & & ready-to-use & DAKO K4011 \\
Anti-rat, peroxidase & & ready-to-use & VectorLabs MP-7444 \\
\hline
\end{tabular}

specific hematopoietic lineages within the BM changed. Specifically, we found an increase in the CD11b ${ }^{+}$myeloid cells (the majority of which are monocytes) in hypoxiaexposed animals (from $36.10 \pm 5.60$ to $48.38 \pm 5.86 \%$ ), and a modulation in the lymphoid compartment, with a significant increase in $\mathrm{CD} 19^{+} \mathrm{B}$ cells $(18.07 \pm 4.55 \%$ in normoxia and $28.90 \pm 5.40 \%$ in $\mathrm{CIH}$ ) and a decrease in the percentage of $\mathrm{CD}^{+} \mathrm{T}$ lymphocytes $(2.74 \pm 0.18$ and $1.70 \pm 0.26 \%$ in normoxia and $\mathrm{CIH}$ exposed rats, respectively) (Fig. 2b-d). Although we did not observe a significant variation in the percentage of $\mathrm{CD}^{+} 0^{+} / \mathrm{c}-\mathrm{kit}^{+}$stem and progenitor cells by flow cytometry (Fig. 2a and a'), in vitro colony-forming units (CFU) assays revealed an increase in 1.5-fold in the total number of CFUs in animals from the CIH group (Fig. 2f). Such assays allowed us to identify and count single-cell derived colonies, representing either multipotent (CFU-granulocyte-erythrocyte-macrophage-megakaryocyte, CFU-GEMM) or monopotent (CFU-monocyte, CFU-M; CFU-granulocyte, CFU-G or bursting forming units-erythrocyte, BFU-E) progenitors. Our data show that chronic intermittent hypoxia treatment significantly increased CFU-M, CFU-G and BFUE colony numbers, without significant alterations in the multipotent capacity (CFU-GEMM) of treated rats (Fig. 2g). Although these results suggest $\mathrm{CIH}$ favors the expansion of monopotent progenitors, we cannot rule out the possibility that the monopotent progenitors arose from more primitive multipotent progenitors.

Having characterized the changes in BM hematopoietic lineages accounted to $\mathrm{CIH}$ exposure, we asked whether these alterations could also be identified in peripheral blood (PB). Indeed, as shown in Fig. 3, we observed a significant increase in erythrocyte counts, in hemoglobin and in the hematocrit of CIH exposed rats (Fig. 3a). Our data also shows a decrease in circulating lymphocytes and an increase in monocytes upon CIH exposure (Fig. 3b), a finding that was also confirmed by flow cytometry, showing increased $\mathrm{CD} 1 \mathrm{~b}^{+}$myeloid cells in the PB (Fig. 2e). In contrast, leukocyte and granulocyte (eosinophil and neutrophil) counts were not affected by CIH. Platelet counts and mean platelet volume were also similar in the $\mathrm{CIH}$ and normoxia groups (Fig. 3c).
Our data thus mimic some of the clinical aspects observed in OSA patients, as we observed no changes in platelet counts, but fails to reproduce other symptoms, such as the increase in platelet activation and aggregation, as assessed by mean platelet volume. Moreover, we report for the first time an increase in the myeloid compartment, both the BM and PB and a modulation in the percentage of B and T lymphocytes in the BM of animals exposed to $\mathrm{CIH}$.

\section{Chronic intermittent hypoxia affects the bone marrow vasculature and modulates monocyte counts}

Having shown that exposure of rats to $\mathrm{CIH}$ perturbs hematopoiesis, as evidenced by changes in circulating mononuclear cell and erythrocyte counts, next we sought to characterize the phenotypic and molecular alterations that occurred in the BM microenvironment that could account for such changes. As shown in Fig. 4, the BM vasculature of CIH exposed animals suffered "phenotypic alterations," as shown by the significant increase in VE-cadherin expressing vessels (Fig. 4c', c") and their VE-cadherin coverage (Fig. 4f), the increase in smooth muscle cell coverage (Fig. 4d', d"), and the decrease in the number of vessels that were positive for vWF (Fig. 4a', a"). In contrast, endoglin (CD105)-expressing vessels did not vary upon CIH exposure (Fig. 4b', b"). Similarly, the BM megakaryocyte content (also assessed by vWF staining) did not vary with CIH exposure (Fig. 4a', a"').

To demonstrate that there was undoubtedly an increased expansion of myeloid cells within the BM, we assessed the $\mathrm{BM} \mathrm{CD} 11 \mathrm{~b}^{+}$cell (monocyte) content. In accordance with the flow cytometric and complete blood count data, we observed an increment in the number of BM monocytes in $\mathrm{CIH}$ treated animals (Fig. 4e', e").

Together, these data show the BM vasculature and in particular the VE-cadherin and vWF-expressing vessels, and the pericyte/smooth muscle cell vessel coverage are affected by $\mathrm{CIH}$ exposure. This morphological change in BM vessels of $\mathrm{CIH}$-treated animals is accompanied by a significant increase in the number of CD11b+ monocytes. 
Table 2 List of primers used for RT-PCR

\begin{tabular}{|c|c|c|}
\hline Gene & Forward primer $\left(5^{\prime}-3^{\prime}\right)$ & Reverse primer $\left(5^{\prime}-3^{\prime}\right)$ \\
\hline$r H P R T$ & GACCGCTTTTCCCGCGAGCC & TCACGACGCTGGGACTGAGGG \\
\hline$r A d m$ & ACCGCACGGCTCGACACTTC & TCCCACGACTTAGCGCCCAC \\
\hline rAngpt1 & TGATGCCTGTGGCCCTTCCA & CATGGTTTTGCCCCGCAGTGT \\
\hline rAngpt2 & TGTCCGGCGAGGAGTCCAAC & GATTTTGCCCGCCGTGCCTG \\
\hline rBmp4 & AGTTTGTTCAAGATTGGCTCCC & CGACCATCAGCATTCGGTTA \\
\hline$r C d h 2$ & TCTGCACCAGGTTTGGAATGGGT & ACATACGTCCCAGGCTTTGATCCC \\
\hline rCsfl & GCCACCGAGAGGCTACAGGAA & TTTGGACACAGGCCTCGTTCTGTT \\
\hline$r C s f 2$ & GGTCTACGGGGCAACCTCACC & AGTTTCCGGGGTTGGAGGGCA \\
\hline$r C s f 3$ & CCTCGGGGTGGCCCCTACTG & CCCGACGCTGGAAGGCAGAA \\
\hline rCxcl12 & GCATCAGTGACGGTAAGCCA & TCTCAAAGAATCGGCAGGGG \\
\hline$r C x c r 4$ & TGGAGAGCGAGCATTGCC & GCAGGGTTCCTTGTTGGAGT \\
\hline$r D h h$ & TCCCCAACTACAACCCCGA & GCTAGAGCATTCACCCGCTC \\
\hline$r D k k 1$ & CTCTATGAGGGCGGGAACAA & GCAAGGGTAGGGCTGGTAGT \\
\hline rDll1 & TCTCCTGACGACCTCGCAACA & GGTGCCTCTGTGTGGTCAGGC \\
\hline rDll4 & CTGGCCGGGAACCTTCTCACTC & TCTCTGGCCGCAGGTCGTCTC \\
\hline rEpo & CCCTATTTACGGGGTGCTGG & CTGTCTCTGCCCCTGAGTTC \\
\hline$r F g f 1$ & AGGGACAGGAGCGACCAGCA & TACACTTCGCCCGCGCTTTCC \\
\hline$r F g f 2$ & TCCGGGAGAAGAGCGACCCA & CCGGTTCGCACACACTCCCTTG \\
\hline rFlt3l & AGCTCTGAAGCCCTGTATCGGGA & ACTGCACCTCCAGGCACCGA \\
\hline rFlt4 & CCCTGCTTGGTGTCCATTCC & GTCGTCCCACAACACCTCC \\
\hline rHesl & TCAACACGACACCGGACAA & GCTTTGATGACTTTCTGTGCT \\
\hline rHeyl & GCCGACGAGACCGAATCAA & TTCGCAGATCCCTGCTTCTC \\
\hline rHey 2 & CCCTTGCGAGGAGACGACCT & GCTCCCCACGTCGATGGTCT \\
\hline$r H i f 1 \alpha$ & GCTTACACACAGAAATGGCCC & GTCCTCCCCCGGCTTGTTAG \\
\hline$r H i f 2 \alpha$ & CCGCCTCATGTCTCCATGTT & CAGCTTGTTGGACAGGGCTA \\
\hline$r \lg f 1$ & CTTTGCGGGGCTGAGCTGGT & AGCCCCTTGGTCCACACACGAA \\
\hline rIgfbp3 & AAGGCGCTGCTGAATGGCCG & GCTGGGAGGGGAGGTAGGCA \\
\hline rIgfbp5 & ACCTGCCCAACTGTGACCGC & GGCCACGAGAAGGCTTGCACT \\
\hline$r l l 3$ & TGATGCTCTTCCACCAGGGACT & AGTCCTGCAATCCAACGTCCTGA \\
\hline rll6 & CTCTCCGCAAGAGACTTCCAGC & AGGGAAGGCAGTGGCTGTCAA \\
\hline rll11 & CCGACTGGAACGGCTACTTC & CAAGGCTAGGCGAGACATCAAG \\
\hline rJagl & GGAAGGCTGGATGGGTCCTGA & TGCAGGAGCCATGCTTGGGA \\
\hline rJag2 & CGGGCCTCGTCGTCATTCCCT & CAGGCCTCCACGATGAGGGTGA \\
\hline$r K d r$ & CGGTCATCCTCACCAATCCC & CCGATCTGGGGTGGAACATT \\
\hline rKitl & ACAAAACTGGTGGCGAATCTTCCAA & TCCCGGCGACATAGTTGAGGGT \\
\hline rPecam 1 & TGGCTTGAGTGGGCGGATGG & AGCCGGGTGGCTGAGGGAAG \\
\hline rSmad2 & TGTGCAGAGCCCCAACTGTAACCA & GGATTTTGCACACTGTCGCGGG \\
\hline rSmad3 & AGGCCATCACCACGCAGAACG & AGCCGGCCATCCAGTGACCT \\
\hline$r T g f b 1$ & AGCCCGAGGCGGACTACTAC & TGCGTTGTTGCGGTCCACCATT \\
\hline rThpo & TGTCCCCACCCCACTCTGTGC & GTGTGGGGCCTCTCCCCTGA \\
\hline rVcam 1 & CGGAGCCTCAACGGTACTTTGG & GCGAGCGTTTTGTATTCAGGGGA \\
\hline rVegfa & GCACTGGACCCTGGCTTTAC & TCTGCTCCCCTTCTGTCGT \\
\hline
\end{tabular}

Chronic intermittent hypoxia modulates the expression of "angiocrine genes"

Since $\mathrm{CIH}$ affected the $\mathrm{BM}$ vasculature as evidenced by the increased VE-cadherin-expressing vessels, next, we hypothesized the "vascular gene expression" could also be altered.
Therefore, we assessed the expression of the so-called "angiocrine genes," which are expressed by the BM endothelial cells and have been previously shown to be essential for $\mathrm{BM}$ recovery following stresses such as irradiation or exposure to chemotherapy [9]. In detail, we sought for molecular correlates to the phenotypic changes observed in the BM 


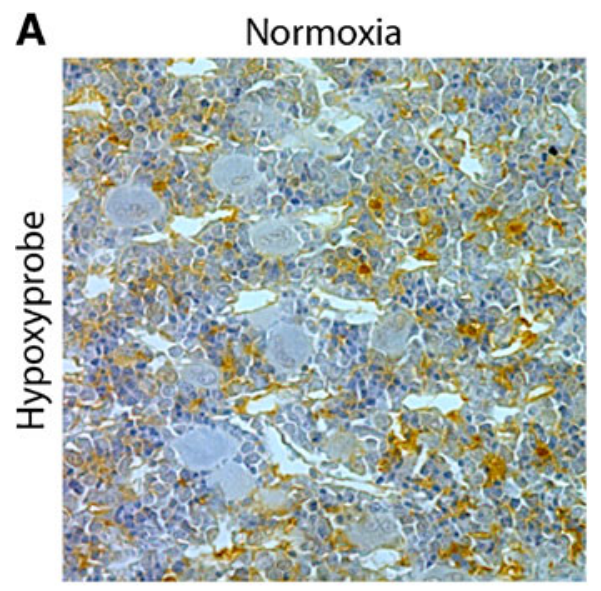

C

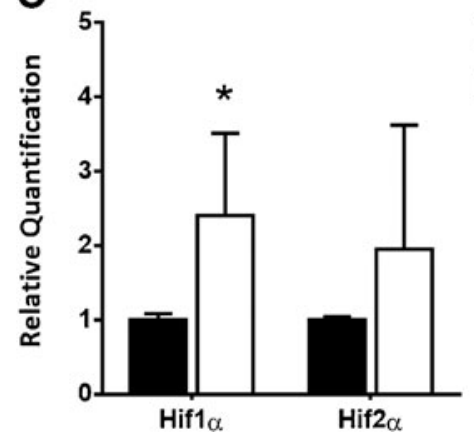

Fig. 1 Chronic intermittent hypoxia affects the hypoxic state of the bone marrow and decreases body weight but does not affect bone marrow cell counts. a The extent of BM hypoxia was increased in animals exposed to $\mathrm{CIH}$, as assessed by pimonidazole staining and $\mathbf{b}$ the significant increase in hypoxic area in $\mathrm{CIH}$ animals. c CIH also have increased Hifla

microenvironment; that is, genes that could explain the increased erythropoiesis, monocytosis, and vascular changes in the BM microenvironment. As shown in Fig. 5, CIH increased the expression of colony-stimulating factor 1 (Csfl), previously shown to modulate monocyte differentiation, proliferation, and survival [63]. Moreover, Vegfa, delta-like 4 (Dll4), angiopoietin 1 (Angpt1) and Fms-like tyrosine kinase 4 (Flt4) also increased upon CIH exposure (Fig. 5), suggesting these may be involved in the vascular response observed in the $\mathrm{BM}$ of $\mathrm{CIH}$-exposed animals, namely, the increase in VEcadherin-expressing and SMA-covered BM vessels.

\section{Discussion}

Chronic intermittent hypoxia $(\mathrm{CIH})$ was first reported by Fletcher and colleagues as a model for obstructive sleep apnea [25]. In their protocol, mice were exposed to cycles of intermittent hypoxia for $7 \mathrm{~h}$ each day for 35 days and were found to develop a long-term hypertensive response to $\mathrm{CIH}$, as it is observed in OSA patients. Such model fails to reproduce the transient hypercapnia that is observed in OSA patients,
B

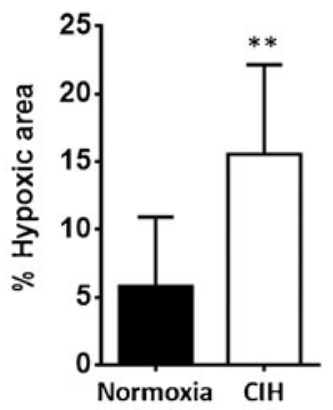

E

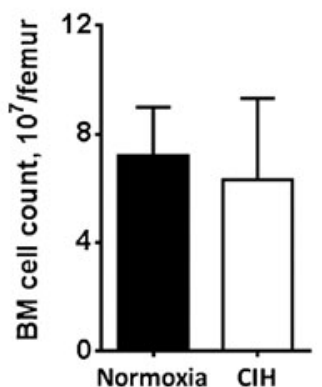

expression. d Rats subjected to $\mathrm{CIH}$ had a lower body weight than controls. e Total BM cell count shows that $\mathrm{CIH}$ does not modify BM cellularity. Results are represented as the mean $\pm \mathrm{SD}$ of bone marrow sections from six male Wistar rats $(* p<0.05 ; * * p<0.01)$

determined by airway occlusion, and mimics only the intermittent hypoxic episodes that occur chronically in these patients, allowing us to separate the mechanical component of obstruction from the effect of intermittent hypoxia itself. In fact, the main goal of our work was to explore the effects of $\mathrm{CIH}$ by itself in the BM vascular compartment. Additionally, over the years, several other groups have shown that this rat model of CIH mimics many aspects of the obstructive sleep apnea syndrome, such as atherosclerosis and alterations in the hematological parameters (for a review see [16]), and only few have manipulated the $\mathrm{CO}_{2}$ levels inside the chambers $[19,36,58]$.

It remains unclear whether the partial pressure of $\mathrm{CO}_{2}$ in the arterial blood $\left(\mathrm{PaCO}_{2}\right)$ is relevant in humans. Hypercapnia is not a standard parameter analyzed in polysomnographic recordings in patients and therefore there is no consensus on the impact of $\mathrm{PaCO}_{2}$ in arterial blood pressure and other parameters in patients with OSA. For instance, in clinical studies of patients with moderate OSA, the changes in $\mathrm{PaCO}_{2}$ have seemed to be irrelevant [24] or have shown a slight increase [74] during the apneic events. Combining chronic sustained hypoxia with hypercapnia was shown to restore the subcutaneous $\mathrm{PaO}_{2}$ to levels close to the normoxic rats [72] and to 
A

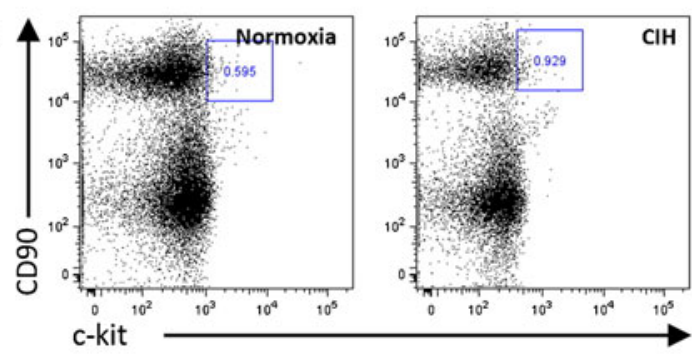

B

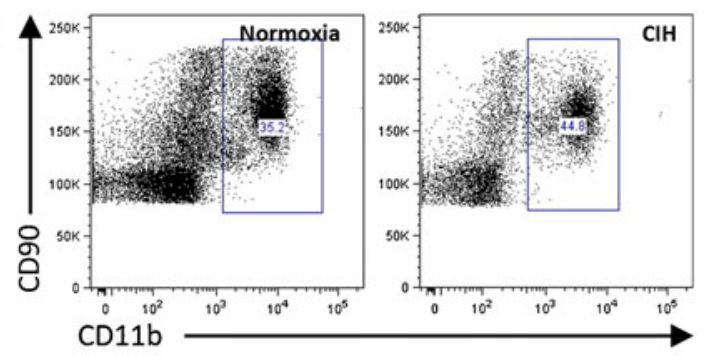

C

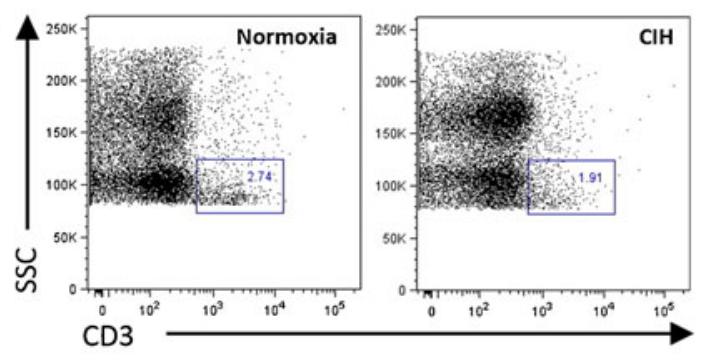

A'

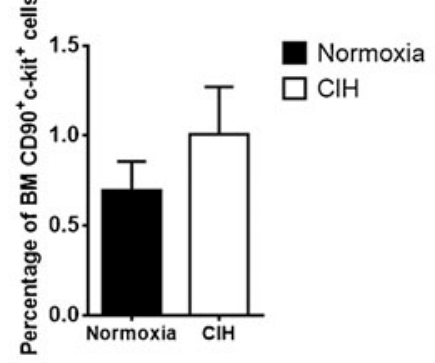

B'

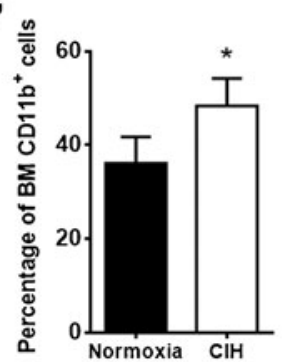

C'

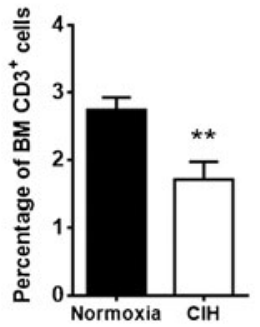

D

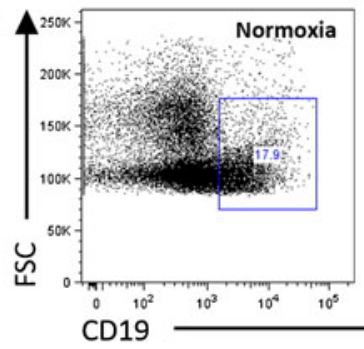

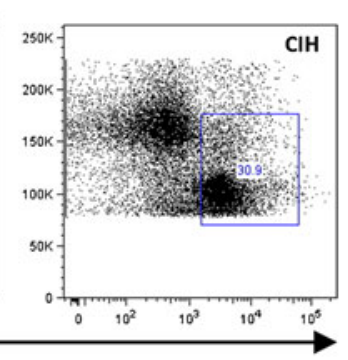

D'

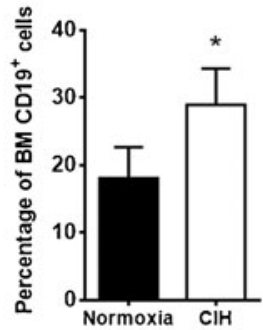

E

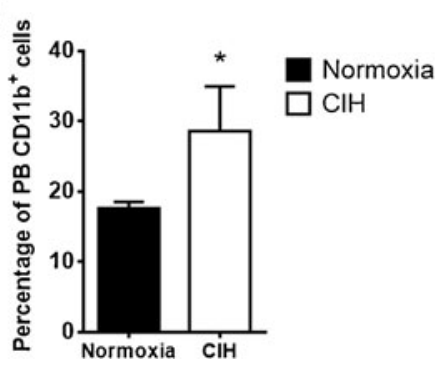

$\mathbf{F}$

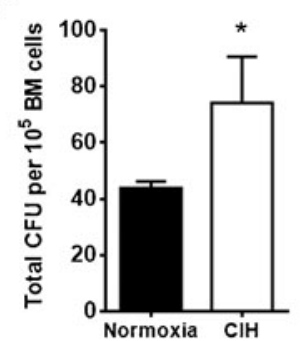

G

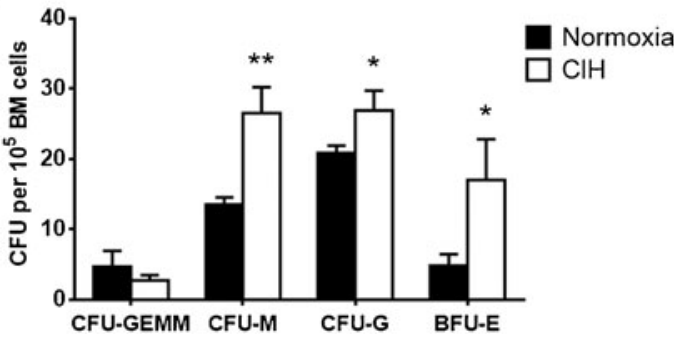

Fig. 2 Rats exposure to chronic intermittent hypoxia affects specific hematopoietic lineages and the commitment of bone marrow progenitor cells. a-d Representative plots of the flow cytometric analysis of bone marrow cells from normoxic $(n=5)$ and $\mathrm{CIH}(n=5)$ exposed rats. Quantification of a' CD90+/c-kit + stem and progenitor cells did not reveal a significant alteration in $\mathrm{CIH}$ animals. However, b' $\mathrm{CD}^{\prime} 1 \mathrm{~b}^{+}$ myeloid- and d' $\mathrm{CD} 19^{+} \mathrm{B}$ cells were increased as opposed to (c') CD3 $\mathrm{T}$ lymphocytes that decreased upon $\mathrm{CIH}$ exposure. e Quantification of

peripheral blood $\mathrm{CD} 11 \mathrm{~b}^{+}$cells by flow cytometry also revealed an increase in the percentage of those cells in circulation. $f$ Colonyforming unit counts from methylcellulose culture of $10^{5} \mathrm{BM}$ cells reveal that $\mathrm{CIH}$ treatment induces an increased the number of HSPC, $\mathbf{g}$ with a particular increase in macrophage, granulocyte and erythroid (CFU-M, CFU-G and BFU-E) colonies. Results are represented as the mean $\pm \mathrm{SD}$ of bone marrow cells from five male Wistar rats $\left({ }^{*} p<0.05 ; * * p<0.01\right)$ 
A
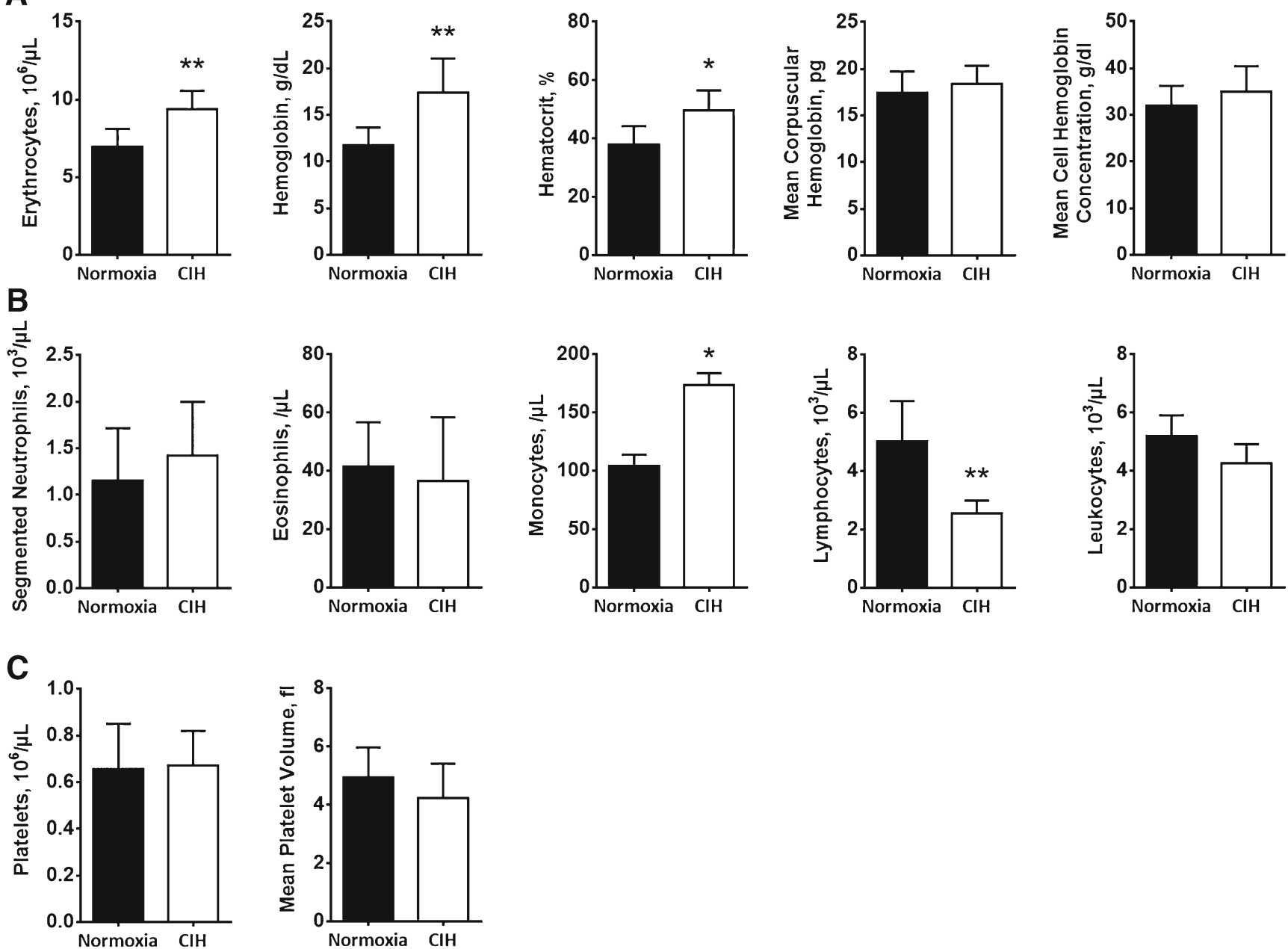

Fig. 3 Chronic intermittent hypoxia modulates circulating blood counts. a CIH may promote erythropoiesis. Erythrocyte, hemoglobin, and hematocrit, as well as mean corpuscular hemoglobin and mean cell hemoglobin concentration were assessed by peripheral blood cell counts. The erythrocyte count, hemoglobin, and hematocrit in $\mathrm{CIH}-$ exposed rats $(n=5)$ are significantly different from those in normoxia

induce a smaller increase in the numbers of circulating erythrocytes [60]. However, the effects of combined $\mathrm{CIH}$ with hypercapnia in the BM microenvironment and hematopoiesis were not yet described. Therefore, although some data suggest that $\mathrm{PaCO}_{2}$ may influence physiological responses to $\mathrm{IH}$, further studies are needed to evaluate the combined effect of $\mathrm{IH}$ and hypercapnia. Only male rats were included in our study to avoid hypothetical effects of estrogens on hematologic responses to chronic intermittent hypoxia since it has been described that $17 \beta$-estradiol can influence the expression of hypoxia-inducible genes such as VEGF and endothelin-1 [2] and decreases hypoxic induction of erythropoietin gene expression $[20,54,80]$.

In this study, we report that $\mathrm{CIH}$ induces a deviation from the normal body weight gain observed in normoxia-exposed rats. These results are consistent with those obtained in a parallel study, where the effects of chronic intermittent hypoxia

$(n=5)(* p<0.05)$. b CIH increases circulating monocytes and decrease lymphocytes. However, peripheral blood cell counts showed no differences in neutrophils, eosinophils, or leukocytes. c Platelet count and mean platelet volume are not modified by exposure to CIH. Results are represented as the mean $\pm \mathrm{SD}$ of blood samples from five male Wistar rats $(* p<0.05 ; * * p<0.01)$

on body weight of male Wistar rats from the NOVA Medical School colony were evaluated. We observed (unpublished

Fig. 4 Chronic intermittent hypoxia modifies the BM vascular structure. a'-e' Representative images of femur bone marrow stained with $\mathrm{vWF}$, CD105, VE-cadherin, SMA, and CD11b counterstained with hematoxylin. a", c", d" BM from $\mathrm{CIH}$ exposed rats $(n=6)$ has more VE-cadherin $^{+}$vessels and SMA coverage but less $\mathrm{vWF}^{+}$sinusoids (400×, Leica DM2500). e', e" Representative images of CD11b immunohistochemistry in femur BM show an increase in BM monocyte count in CIH exposed animals. (400×, Leica DM2500) a', a"', b', b" No changes in the total number of vessels or in megakaryocyte count were observed, as accounted by CD105 and vWF staining, respectively. Results are represented as the mean $\pm \mathrm{SD}$ of bone marrow sections from six male Wistar rats $\left({ }^{*} p<0.05 ;{ }^{* *} p<0.01\right)$. f Representative images of femur bone marrow fluorescently immunostained for VE-cadherin show an increase in total VE-cadherin vessels and in VE-cadherin vessel coverage. Scale bar, $50 \mu \mathrm{m}$ (insets magnified $2.5 \times$ ). Images were acquired with a Zeiss LSM 510 META microscope 

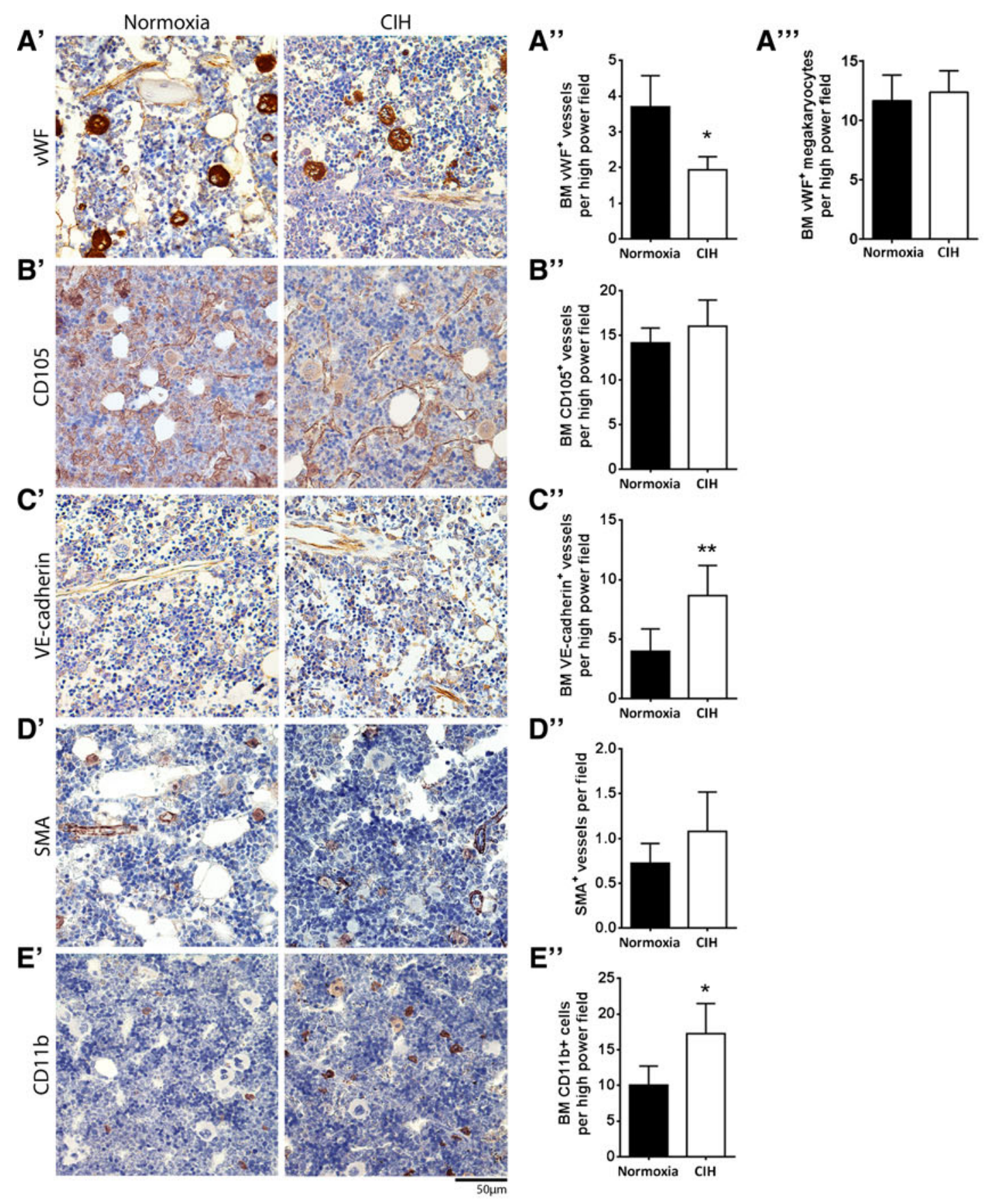

\section{B'}

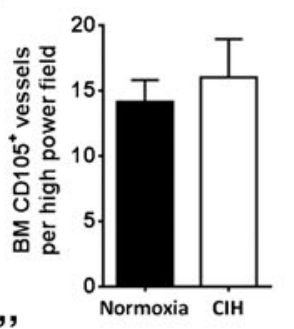

C"'

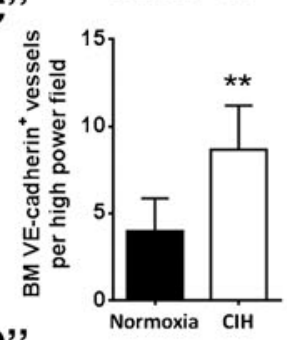

D"

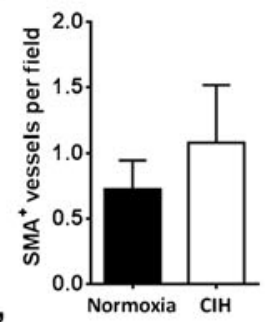

E'

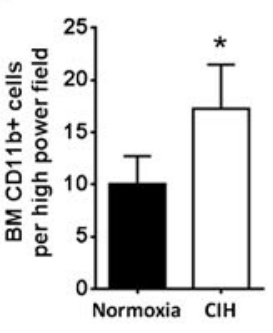

F

Normoxia
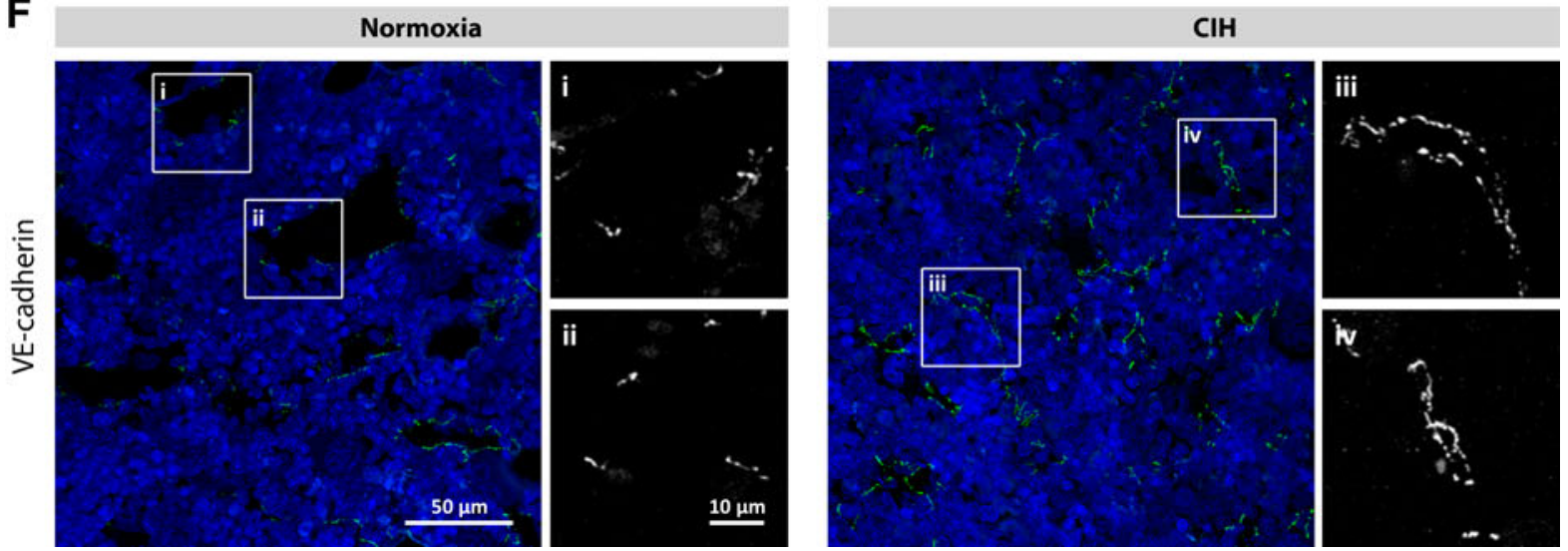
A
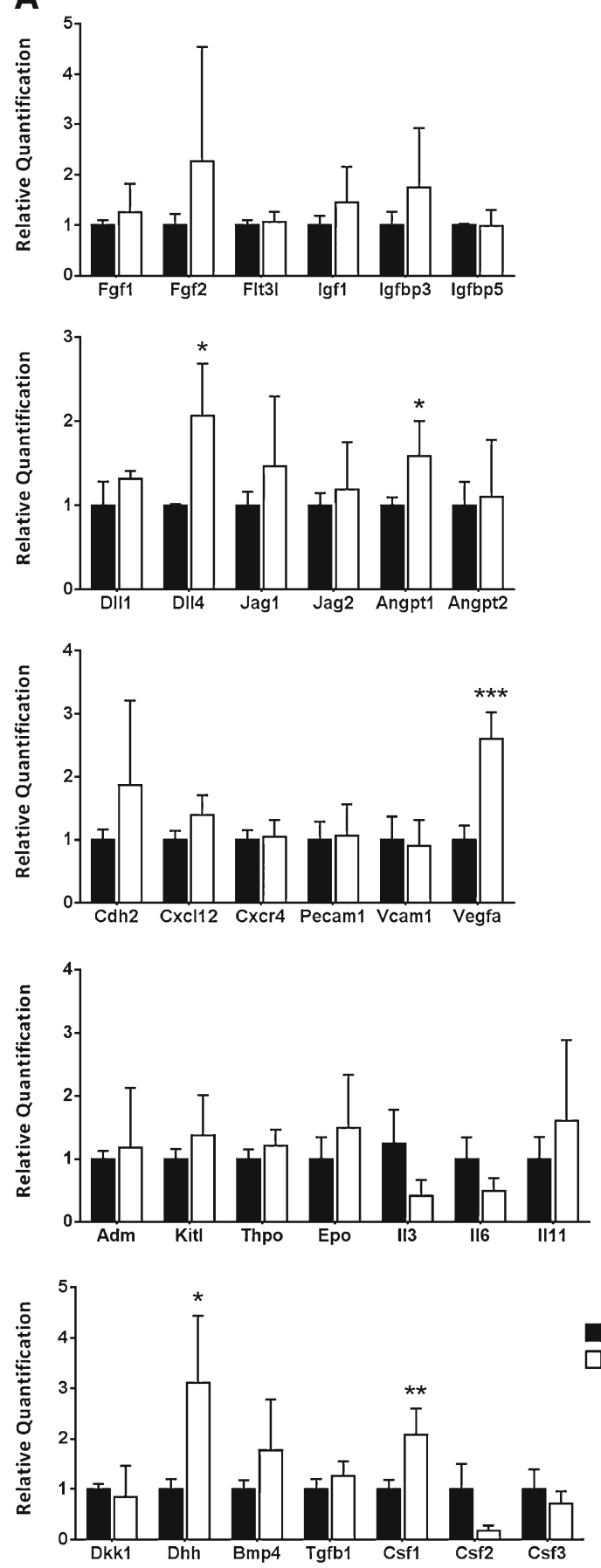

Fig. 5 Chronic intermittent hypoxia modulates bone marrow angiocrine gene expression. a Angiocrine gene modulation was assessed by relative quantification of mRNA of total BM samples from normoxia $(n=6)$ and $\mathrm{CIH}(n=6)$ treated rats. As determined by RT-PCR, we observed an

data) that rats exposed to 35 days of $\mathrm{CIH}$ weighed significantly less compared with age-matched healthy male Wistar rats kept in normoxia. Several authors reported a weight loss of CIH-exposed rats when compared with control rats $[69,70$, $75,85]$. Such alteration in body weight might be explained by the production and release of leptin into the circulation as a

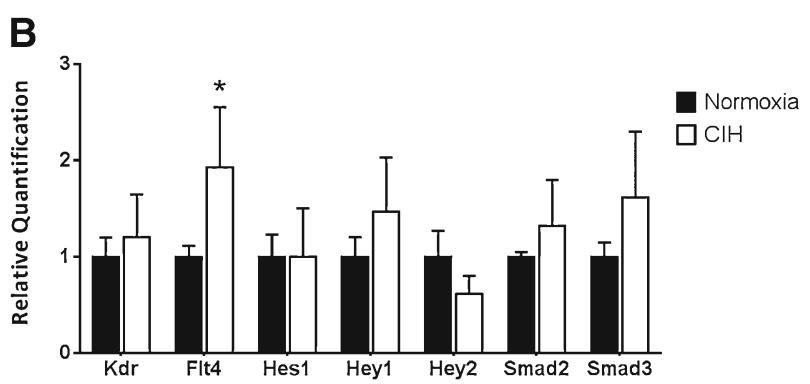

increase in Vegfa, Dll4, Angpt1, Dhh, and Csf1. b In addition, we also measured an increase in the expression of Flt4. Data are represented as mean \pm SD of six male Wistar rats $\left({ }^{*} p<0.05 ; * * p<0.01 ; * * * p<0.001\right)$

response to hypoxia $[1,39,51,53,76,81]$. Leptin is coded by an hypoxia inducible gene that acts upon the hypothalamus to control body weight by reducing food intake and increasing energy expenditure [31, 59, 81]. Moreover, leptin-deficient mice exposed to $\mathrm{CIH}$ have a normal weight gain, compared to normoxic mice [79], indicating that this is a specific leptin- 
dependent mechanism rather than just a stress response. In our study, the lower body weight may be due to a higher metabolic activity in the hypoxic rats, as we did not observe significant differences in caloric consumption between the two groups of animals, but this assumption needs further validation.

The increased risk of CIH and OSA patients to develop cardiovascular complications led us to hypothesize that a systemic mechanism might be involved in the pathophysiology of such co-morbidities. The recruitment of bone marrowderived cells has been amply demonstrated to be involved in the onset and progression of cardiovascular diseases [78]. The involvement of BM cells has, for instance, been shown to be important in the setting of atherosclerosis [28] and has also been implicated in hypertension [78]. Therefore, in the present study, we explored the hypothesis that $\mathrm{CIH}$ might affect the $\mathrm{BM}$ microenvironment and therefore affect hematopoiesis.

Here, we show a significant increase in BM and PB myeloid (monocyte) counts in animals exposed to $\mathrm{CIH}$, accompanied by an increase in the total monocyte and granulocyte progenitor cell-derived CFUs (CFU-M and CFU-G). Several studies reported an increase in circulating granulocytes both in acute and chronic hypoxia [14, 61] and increased neutrophil and lymphocyte counts in the upper airway mucosa of OSA patients $[29,68]$. Interestingly, a significantly lower percentage of macrophages was found in the mucosa of these patients [68]. Nevertheless, chronic intermittent hypoxia increases the amount of pro-inflammatory pulmonary macrophages [56]. No reports of changes in circulating monocyte or in BM myeloid counts as a response to hypoxia exposure were found. However, Roiniotis and his colleagues showed that hypoxia can have a pro-survival effect both in monocytes and macrophages [66] and Yoon described decreased myelopoiesis in Hifla $^{-/-}$embryos [82], suggesting a positive correlation between hypoxia exposure and expansion of the myeloid compartment. Our data also shows that CIH can modulate the BM lymphocyte content, a finding that had not been described either in CIH-exposed rats or OSA patients. DomagalaKulawik and her colleagues described a decrease in circulating B cells and an increase in several T lymphocyte subsets in OSA patients, but they addressed only peripheral blood and not BM lymphocyte content [17]. Furthermore, our data is consistent with previous reports showing that stabilization of Hifl $\alpha$ and Hif $2 \alpha$ in thymocytes resulted in a remarkable increase in thymocyte apoptosis $[4,13]$ and that HIF $1 \alpha$ deficient chimeric mice have impaired B cell development with decreased proliferation of B cell progenitors [38].

In addition, we report an increment in circulating erythrocytes and in blood hemoglobin and hematocrit, which correlates with the higher numbers of erythroid colonies (BFU-E) derived from BM progenitors. This increase in erythroid colonies was also described in rats exposed to chronic sustained hypoxia (4 weeks). However, the authors of that study failed to detect any remarkable alterations in granulocyte-macrophage progenitor numbers [67]. Previous studies have shown that acute and chronic sustained [83] or intermittent hypoxia promoted erythropoiesis [5, 46, 49, 50, 64]. Furthermore, although there is a general lack of healthy controls in most studies, clinical data of OSA patients also suggest an increase in hemoglobin levels [12, 30] and in hematocrit [22, 32], and diurnal variations in erythropoietin levels [10] which together seem to be correlated with the severity of OSA $[12,77]$. The effects of hypoxia in platelet parameters are dependent on the hypoxia administration. In detail, short-term chronic sustained hypoxia (1-4 days) was reported to promote thrombocytosis [44]. However, after 4-5 days of exposure, platelet counts returned to normal and thereafter rapidly declined between the fifth and the ninth days of hypoxia, leveling off at half their normal value $[44,48]$. Studies in chronic intermittent asphyxia, however, have shown it does not affect platelet count, but instead increases platelet activation and aggregation [18], an effect that is correlated with the severity of the disease in OSA patients [35]. These results deserve further studies but emphasize the differences between sustained and intermittent hypoxia.

One interesting observation in bone marrow sections of animals in $\mathrm{CIH}$ was the significant increase in VE-cadherinexpressing vessels and in smooth muscle cell coverage, accompanied by a decrease in the vWF-positive vessels. However, we did not observe an increase in total vessel number assessed by CD105 expression. These findings highlight the heterogeneity of the vascular content of the BM microenvironment (similar findings, in a different context were reported in Remedio et al. 2012) [65] and demonstrate that different vascular markers should be used concomitantly, to avoid misinterpretation of single marker-staining patterns.

These morphological changes in bone marrow vessels upon $\mathrm{CIH}$ exposure are also indicative of a molecular process which appears to be favoring vascular stability. vWF is associated with activated and thus less stable vessels, since it is upregulated in endothelial cells treated with FGF2 and VEGF (potent angiogenic inducers) [84]. Contrastingly, VE-cadherin expression and smooth muscle coverage have been associated with increased vessel stability [21], usually induced after an active angiogenic (generating new vessels) process [55]. HIF $1 \alpha$, that we found to be upregulated in hypoxic rats, is one of the major inducers of angiogenesis, as it upregulates Vegf expression, ultimately leading to vessel permeability and instability [23, 41, 47, 71]. This process is tightly coupled with a decrease of VE-cadherin in the endothelial tight junctions [37, 47], in a VEGF-dependent manner. Our data suggest that the BM sinusoids may not be responding to the proangiogenic effects of VEGF and instead become more stable upon hypoxia exposure. Additionally, the reported increase in SMApositive vessels in CIH-exposed rats is suggestive of vessel stabilization. This is in line with the findings that hypoxia promotes endothelial cell activation which will lead to the release of mitogenic factors for smooth muscle cells [33, 52]. 
An understanding of the role of vessels (and of endothelial cells that comprise them) in organ function and recovery following injury has dramatically changed in the last years. It is now accepted that endothelial cells within each organ express a different subset of trophic growth factors, known as "angiocrine factors," that will satisfy the function and metabolic demands of that specific organ. Moreover, ECs play an active role in organ recovery, through an adaptation of the expression of these trophic factors, supporting the regeneration and proliferation of stem and progenitor cells in the affected tissues, in a paracrine manner. [8, 9, 57]. In the present study, we reasoned the vascular changes seen in the bone marrows of animals exposed to $\mathrm{CIH}$ might affect the production of specific angiocrine factors; identification of such factors could in turn explain the alterations in hematopoiesis seen in $\mathrm{CIH}$ animals. We observed significant changes in the expression of Csfl, which explains the increase in BM and PB myeloid compartment [11], and in the levels of Vegfa and Angptl. Vegf is an hypoxia-inducible gene and is most likely upregulated in response to the increased levels of Hifl $\alpha$ in hypoxic rats. Angiopoietin 1 (Angpt1) in particular has been shown to modulate vessel stability by promoting the chemoattraction of smooth muscle cells to newly formed vessels [73], usually in response to augmented VEGF levels [27]. Additionally, Angpt1 protects blood vessels from VEGF-induced permeability by inhibiting internalization of VE-cadherin which leads to an increase in VE-cadherin expression and vessel stabilization [26, 27]. Together, these molecular findings correlate with the vascular changes observed in the bone marrow of animals exposed to $\mathrm{CIH}$.

Taken together, our data obtained from an animal model of OSA, reveal that the systemic effects of $\mathrm{CIH}$ result in modulation of the bone marrow microenvironment, namely, the bone marrow vasculature, which in turn might be perturbing hematopoiesis. Our results pave the way for pre-clinical and clinical studies aimed at validating these findings in OSA patients.

Acknowledgments The authors thank the Neo-vascularization Lab members for their input and suggestions.

This study was supported by Fundação para a Ciência e Tecnologia (FCT, Portuguese Government) grants and fellowships.

Open Access This article is distributed under the terms of the Creative Commons Attribution 4.0 International License (http:// creativecommons.org/licenses/by/4.0/), which permits unrestricted use, distribution, and reproduction in any medium, provided you give appropriate credit to the original author(s) and the source, provide a link to the Creative Commons license, and indicate if changes were made.

\section{References}

1. Ambrosini G, Nath AK, Sierra-Honigmann MR, Flores-Riveros J (2002) Transcriptional activation of the human leptin gene in response to hypoxia. Involvement of hypoxia-inducible factor 1 . J Biol Chem 277:34601-34609. doi:10.1074/jbc.M205172200
2. Bausero P, Ben-Mahdi M-H, Mazucatelli J-P, Bloy C, PerrotApplanat M (2000) Vascular endothelial growth factor is modulated in vascular muscle cells by estradiol, tamoxifen, and hypoxia. Am J Physiol Heart Circ Physiol 279:H2033-H2042

3. Beran M (1973) Hemopoietic recovery in posthypoxic mice: repopulation of CFUs and morphologically identifiable cells in the bone marrow and spleen. Radiat Res 53:468-479

4. Biju MP, Neumann AK, Bensinger SJ, Johnson RS, Turka LA, Haase VH (2004) Vhlh gene deletion induces Hif-1-mediated cell death in thymocytes vhlh gene deletion induces Hif-1-mediated cell death in thymocytes $\uparrow$. Mol Cell Biol 24:9038-9047. doi:10.1128/ MCB.24.20.9038

5. Boyum A, Carsten AL, Laerum OD, Cronkite EP (1972) Kinetics of cell proliferation of murine bone marrow cells cultured in diffusion chambers: effect of hypoxia, bleeding, erythropoietin injections, polycythemia, and irradiation of the host. Blood 40:174-188

6. Bradley TR, Metcalf D (1966) The growth of mouse bone marrow cells in vitro. Aust J Exp Biol Med Sci 44:287-299

7. Briançon-Marjollet A, Pépin J-L, Weiss JW, Lévy P, Tamisier R (2014) Intermittent hypoxia upregulates serum VEGF. Sleep Med 6-7. doi: 10.1016/j.sleep.2014.07.006

8. Butler JM, Kobayashi H, Rafii S, Manuscript A (2010) Instructive role of the vascular niche in promoting tumour growth and tissue repair by angiocrine factors. Nat Rev Cancer 10:138-146. doi:10. 1038/nrc2791.Instructive

9. Butler JM, Nolan DJ, Vertes EL, Varnum-finney B, Hooper AT, Seandel M, Shido K, White IA, Witte L, May C, Shawber C, Kimura Y, Kitajewski J, Rosenwaks Z, Bernstein ID, Rafii S (2010) Endothelial cells are essential for the self-renewal and repopulation of Notch-dependent hematopoietic stem cells. 6:251264. doi: 10.1016/j.stem.2010.02.001.Endothelial

10. Cahan C, Decker MJ, Arnold JL, Washington LH, Veldhuis JD, Goldwasser E, Strohl KP (1992) Diurnal variations in serum erythropoietin levels in healthy subjects and sleep apnea patients. J Appl Physiol 72:2112-2117

11. Chitu V, Stanley ER (2006) Colony-stimulating factor-1 in immunity and inflammation. Curr Opin Immunol 18:39-48. doi:10.1016/ j.coi.2005.11.006

12. Choi JB, Loredo JS, Norman D, Mills PJ, Ancoli-Israel S, Ziegler MG, Dimsdale JE (2006) Does obstructive sleep apnea increase hematocrit? Sleep Breath 10:155-160. doi:10.1007/s11325-0060064-z

13. Clambey ET (2013) Hypoxia and hypoxia-inducible factors as regulators of $\mathrm{T}$ cell development, differentiation and function. Immunol Res 55:58-70. doi:10.1007/s12026-012-8349-8.Hypoxia

14. Coates G, Nahmias C, Thind A (1983) Platelets and leukocytes in the lungs after acute hypobaric hypoxia. J Appl Physiol 55:15361541

15. Coulombel L (2004) Identification of hematopoietic stem/ progenitor cells: strength and drawbacks of functional assays. Oncogene 23:7210-7222. doi:10.1038/sj.onc.1207941

16. Diogo LN, Monteiro EC (2014) The efficacy of antihypertensive drugs in chronic intermittent hypoxia conditions. Front Physiol 5: 361. doi:10.3389/fphys.2014.00361

17. Domagala-Kulawik J, Osinska I, Piechuta A, Bielicki P, Skirecki T (2015) T, B, and NKT cells in systemic inflammation in obstructive sleep apnoea. Mediat Inflamm

18. Dunleavy M, Dooley M, Cox D, Bradford A (2005) Chronic intermittent asphyxia increases platelet reactivity in rats. Exp Physiol 90: 411-416. doi:10.1113/expphysiol.2004.029306

19. Dyavanapalli J, Jameson H, Dergacheva O, Jain V, Alhusayyen M, Mendelowitz D (2014) Chronic intermittent hypoxia-hypercapnia blunts heart rate responses and alters neurotransmission to cardiac vagal neurons. J Physiol 592:2799-2811. doi:10.1113/jphysiol. 2014.273482 
20. Ebert BL, Bunn HF (1999) Regulation of the erythropoietin gene. Blood 94:1864-1877. doi:10.1097/00062752-199502020-00004

21. Eisa-Beygi S, Macdonald RL, Wen X-Y (2014) Regulatory pathways affecting vascular stabilization via VE-cadherin dynamics: insights from zebrafish (Danio rerio). J Cereb Blood Flow Metab 34:1430-1433. doi:10.1038/jcbfm.2014.128

22. Eisensehr I, Noachtar S (2001) Haematological aspects of obstructive sleep apnoea. Sleep Med Rev 5:207-221. doi:10.1053/smrv. 2001.0158

23. Engelhardt S, Al-Ahmad AJ, Gassmann M, Ogunshola OO (2014) Hypoxia selectively disrupts brain microvascular endothelial tight junction complexes through a hypoxia-inducible factor-1 (HIF-1) dependent mechanism. J Cell Physiol 229:1096-1105. doi:10. $1002 /$ jcp. 24544

24. Epstein LJ, Jervis OJ, Henderson JH, Sullivan M, Mohsenifar Z (2001) Measurement of gastric $\mathrm{P}(\mathrm{CO} 2)$ as an index of tissue hypoxia during obstructive sleep apnea. Respiration 68:28-34. doi: 50459

25. Fletcher EC, Lesske J, Qian W, Miller CC, Unger T (1992) Repetitive, episodic hypoxia causes diurnal elevation of blood pressure in rats. Hypertension 19:555-561. doi:10.1161/01.HYP.19.6. 555

26. Gavard J (2009) Breaking the VE-cadherin bonds. FEBS Lett 583: 1-6. doi:10.1016/j.febslet.2008.11.032

27. Gavard J, Patel V, Gutkind JS (2008) Angiopoietin-1 prevents VEGF-induced endothelial permeability by sequestering Src through mDia. Dev Cell 14:25-36. doi:10.1016/j.devcel.2007.10. 019

28. Ghattas A, Griffiths HR, Devitt A, Lip GYH, Shantsila E (2013) Monocytes in coronary artery disease and atherosclerosis: where are we now? J Am Coll Cardiol 62:1541-1551. doi:10.1016/j. jacc.2013.07.043

29. Hauber H-P, Rüller S, Müller E, Hansen E, Zabel P (2011) Pharyngeal lavage lymphocytosis in patients with obstructive sleep apnea: a preliminary observation. PLoS One 6, e16277. doi:10. 1371/journal.pone.0016277

30. Heinicke K, Prommer N, Cajigal J, Viola T, Behn C, Schmidt W (2003) Long-term exposure to intermittent hypoxia results in increased hemoglobin mass, reduced plasma volume, and elevated erythropoietin plasma levels in man. Eur J Appl Physiol 88:535543. doi:10.1007/s00421-002-0732-z

31. Hill JW, Williams KW, Ye C, Luo J, Balthasar N, Coppari R, Cowley MA, Cantley LC, Lowell BB, Elmquist JK (2008) Acute effects of leptin require PI3K signaling in hypothalamic proopiomelanocortin neurons in mice. J Clin Invest 118:17961805. doi:10.1172/JCI32964

32. Hoffstein V, Herridge M, Mateika S, Redline S, Strohl KP (1994) Hematocrit levels in sleep apnea. Chest 106:787-791

33. Humar R, Kiefer FN, Berns H, Resink TJ, Battegay EJ (2002) Hypoxia enhances vascular cell proliferation and angiogenesis in vitro via rapamycin (mTOR)-dependent signaling. FASEB J 16: 771-780. doi:10.1096/fj.01-0658com

34. Imanirad P, Dzierzak E (2013) Hypoxia and HIFs in regulating the development of the hematopoietic system. Blood Cells Mol Dis 51: 256-263. doi:10.1016/j.bcmd.2013.08.005

35. Kanbay A, Tutar N, Kaya E, Buyukoglan H, Ozdogan N, Oymak FS, Gulmez I, Demir R (2013) Mean platelet volume in patients with obstructive sleep apnea syndrome and its relationship with cardiovascular diseases. Blood Coagul Fibrinolysis 24:532-536. doi:10.1097/MBC.0b013e32835e98da

36. Kantores C, McNamara PJ, Teixeira L, Engelberts D, Murthy P, Kavanagh BP, Jankov RP (2006) Therapeutic hypercapnia prevents chronic hypoxia-induced pulmonary hypertension in the newborn rat. Am J Physiol Lung Cell Mol Physiol 291:L912-L922. doi:10. 1152/ajplung.00480.2005
37. Kobayashi S, Yamashita T, Ohneda K, Nagano M, Kimura K, Nakai H, Poellinger L, Ohneda O (2015) Hypoxia-inducible factor- $3 \alpha$ promotes angiogenic activity of pulmonary endothelial cells by repressing the expression of the VE-cadherin gene. Genes Cells. doi:10.1111/gtc. 12215

38. Kojima H, Gu H, Nomura S, Caldwell CC, Kobata T, Carmeliet P, Semenza GL, Sitkovsky MV (2002) Abnormal B lymphocyte development and autoimmunity in hypoxia-inducible factor 1alpha deficient chimeric mice. Proc Natl Acad Sci U S A 99:2170-2174. doi:10.1073/pnas.052706699

39. Koob GF, Annau Z, Rubin RJ, Montgomery MR, Robert J (1974) Effect of hypoxic hypoxia and carbon monoxide on food intake, water intake, and body weight in two strains of rats. Life Sci 14: 1511-1520. doi:10.1016/0024-3205(74)90162-3

40. Kopp H-G, Avecilla ST, Hooper AT, Rafii S (2005) The bone marrow vascular niche: home of HSC differentiation and mobilization. Physiology 20:349-356. doi:10.1152/physiol.00025.2005

41. Koto T, Takubo K, Ishida S, Shinoda H, Inoue M, Tsubota K, Okada Y, Ikeda E (2007) Hypoxia disrupts the barrier function of neural blood vessels through changes in the expression of claudin-5 in endothelial cells. Am J Pathol 170:1389-1397. doi:10.2353/ ajpath.2007.060693

42. Krieger J, Sforza E, Barthelmebs M, Imbs J-L, Kurtz D (1990) Overnight decrease in hematocrit after nasal CPAP treatment in patients with OSA. Chest 97:729-730

43. Lavie L, Kraiczi H, Hefetz A, Ghandour H, Perelman A, Hedner J, Lavie P (2002) Plasma vascular endothelial growth factor in sleep apnea syndrome: effects of nasal continuous positive air pressure treatment. Am J Respir Crit Care Med 165:1624-1628. doi:10. 1164/rccm.20110-040OC

44. Lebedeva EV, Yushkov BG, Chereshnev VA (2003) Megakaryocytopoiesis under hypoxic conditions. Bull Exp Biol Med 136:554-556

45. Lippl FJ, Neubauer S, Schipfer S, Lichter N, Tufman A, Otto B, Fischer R (2010) Hypobaric hypoxia causes body weight reduction in obese subjects. Obesity (Silver Spring) 18:675-681. doi:10. 1038/oby.2009.509

46. Lord BIL, Murphy MJ (1973) Hematopoietic stem cell regulation.I. Acute effects of hypoxic-hypoxia on CFU kinetics. Blood 42:8187

47. Makarenko VV, Usatyuk PV, Yuan G, Lee MM, Nanduri J, Natarajan V, Kumar GK, Prabhakar NR (2014) Intermittent hypoxia-induced endothelial barrier dysfunction requires ROSdependent MAP kinase activation. Am J Physiol Cell Physiol 60637:745-752. doi:10.1152/ajpcell.00313.2013

48. McDonald TP, Cottrell M, Clift R (1978) Effects of short-term hypoxia on platelet counts of mice. Blood 51:165-175

49. McGuire M, Bradford A (1999) Chronic intermittent hypoxia increases haematocrit and causes right ventricular hypertrophy in the rat. Respir Physiol 117:53-58

50. McGuire M, Bradford A (2001) Chronic intermittent hypercapnic hypoxia increases pulmonary arterial pressure and haematocrit in rats. Eur Respir J 18:279-285

51. Messenger SA, Ciriello J (2013) Effects of intermittent hypoxia on leptin signalling in the carotid body. Neuroscience 232:216-225

52. Michiels C, Arnould T, Remacle J (2000) Endothelial cell responses to hypoxia: initiation of a cascade of cellular interactions. Biochim Biophys Acta Mol Cell Res 1497:1-10. doi:10.1016/S01674889(00)00041-0

53. Moreau JM, Ciriello J (2013) Effects of acute intermittent hypoxia on energy balance and hypothalamic feeding pathways. Neuroscience 253:350-360. doi:10.1016/j.neuroscience.2013.09. 007

54. Mukundan H, Resta TC, Kanagy NL (2002) 17Beta-estradiol decreases hypoxic induction of erythropoietin gene expression. Am J 
Physiol Regul Integr Comp Physiol 283:R496-R504. doi:10.1152/ ajpregu.00573.2001

55. Murakami M (2012) Signaling required for blood vessel maintenance: molecular basis and pathological manifestations. Int J Vasc Med 2012:293641. doi:10.1155/2012/293641

56. Nagai H, Kuwahira I, Schwenke DO, Tsuchimochi H, Nara A, Ogura S, Sonobe T, Inagaki T, Fujii Y, Yamaguchi R, Wingenfeld L, Umetani K, Shimosawa T, Yoshida K, Uemura K, Pearson JT, Shirai M (2015) Pulmonary macrophages attenuate hypoxic pulmonary vasoconstriction via $\beta 3 \mathrm{AR} / \mathrm{iNOS}$ pathway in rats exposed to chronic intermittent hypoxia. PLoS One 10, e0131923. doi:10. 1371/journal.pone. 0131923

57. Nolan DJ, Ginsberg M, Israely E, Palikuqi B, Poulos MG, James D, Ding B, Schachterle W, Liu Y, Rosenwaks Z, Jason M, Xiang J, Rafii A, Shido K, Rabbany SY, Elemento O (2014) Molecular signatures of tissue-specific microvascular endothelial cell heterogeneity in organ maintenance and regeneration. Dev Cell. doi:10. 1016/j.devcel.2013.06.017.Molecular

58. Ooi H, Cadogan E, Sweeney M, Howell K, O'Regan RG, McLoughlin P (2000) Chronic hypercapnia inhibits hypoxic pulmonary vascular remodeling. Am J Physiol Heart Circ Physiol 278: H331-H338

59. Palmer BF, Clegg DJ (2013) Ascent to altitude as a weight loss method: the good and bad of hypoxia inducible factor activation. Obesity (Silver Spring). doi:10.1002/oby.20499

60. Pepelko WE (1971) Effect of hypoxia and hypercapnia alone and in combination upon the circulating red cell volume of rats. Exp Biol Med 136:967-971. doi:10.3181/00379727-136-35407

61. Petursson SR, Chervenick PA (1987) Effects of hypoxia on megakaryocytopoiesis and granulopoiesis. Eur J Haematol 39: 267-273. doi:10.1111/j.1600-0609.1987.tb00768.x

62. Pugh CW, Ratcliffe PJ (2003) Regulation of angiogenesis by hypoxia: role of the HIF system. Nat Med 9:677-684. doi:10.1038/ nm0603-677

63. Rathinam C, Poueymirou WT, Rojas J, Murphy AJ, Valenzuela DM, Yancopoulos GD, Rongvaux A, Eynon EE, Manz MG, Flavell RA (2011) Efficient differentiation and function of human macrophages in humanized CSF-1 mice. Blood 118:3119-3128. doi:10.1182/blood-2010-12-326926

64. Reissmann KR (1950) Studies on the mechanism of erythropoietic stimulation in parabiotic rats during hypoxia. Blood 5:372-380

65. Remédio L, Carvalho T, Caiado F, Bastos-Carvalho A, Martins D, Duarte A, Yagita H, Dias S (2012) Context- and cell-dependent effects of Delta-like 4 targeting in the bone marrow microenvironment. PLoS One 7, e52450. doi:10.1371/journal.pone.0052450

66. Roiniotis J, Dinh H, Masendycz P, Turner A, Elsegood CL, Scholz GM, Hamilton JA (2009) Hypoxia prolongs monocyte/macrophage survival and enhanced glycolysis is associated with their maturation under aerobic conditions. J Immunol 182:7974-7981. doi:10.4049/ jimmunol.0804216

67. Rolović Z, Basara N, Biljanović-Paunović L, Stojanović N, Suvajdzić N, Pavlović-Kentera V (1990) Megakaryocytopoiesis in experimentally induced chronic normobaric hypoxia. Exp Hematol 18:190-194

68. Salerno F, Carpagnano E, Guido P, Bonsignore M, Roberti A, Aliani M, Vignola A, Spanevello A (2004) Airway inflammation in patients affected by obstructive sleep apnea syndrome. Respir Med 98:25-28

69. Silva AQ, Schreihofer AM (2011) Altered sympathetic reflexes and vascular reactivity in rats after exposure to chronic intermittent hypoxia. J Physiol 589:1463-1476. doi:10.1113/jphysiol.2010.200691

70. Soukhova-O'Hare GK, Ortines RV, Gu Y, Nozdrachev AD, Prabhu SD, Gozal D (2008) Postnatal intermittent hypoxia and developmental programming of hypertension in spontaneously hypertensive rats: the role of reactive oxygen species and L-Ca2+ channels.
Hypertension 52:156-162. doi:10.1161/HYPERTENSIONAHA. 108.110296

71. Stenmark KR, Fagan KA, Frid MG (2006) Hypoxia-induced pulmonary vascular remodeling: cellular and molecular mechanisms. Circ Res 99:675-691. doi:10.1161/01.RES.0000243584.45145.3f

72. Streeter RG, Pepelko WE, Cain SM (1975) Tissue oxygenation and splenic erythropoiesis during chronic hypoxia and hypercapnia. J Appl Physiol 38:309-314

73. Sundberg C, Kowanetz M, Brown LF, Detmar M, Dvorak HF (2002) Stable expression of angiopoietin-1 and other markers by cultured pericytes: phenotypic similarities to a subpopulation of cells in maturing vessels during later stages of angiogenesis in vivo. Lab Investig 82:387-401

74. Tilkian AG, Guilleminault C, Schroeder JS, Lehrman KL, Simmons FB, Dement WC (1976) Hemodynamics in sleepinduced apnea. Studies during wakefulness and sleep. Ann Intern Med 85:714-719

75. Totoson P, Fhayli W, Faury G, Korichneva I, Cachot S, Baldazza M, Ribuot C, Pépin J-L, Lévy P, Joyeux-Faure M (2013) Atorvastatin protects against deleterious cardiovascular consequences induced by chronic intermittent hypoxia. Exp Biol Med (Maywood) 238: 223-232. doi:10.1177/1535370212473696

76. Tschöp M, Strasburger CJ, Hartmann G, Biollaz J, Bärtsch P (1998) Raised leptin concentrations at high altitude associated with loss of appetite. Lancet 352:1119-1120. doi:10.1016/S0140-6736(05) 79760-9

77. Winnicki M, Shamsuzzaman A, Lanfranchi P, Accurso V, Olson E, Davison D, Somers VK (2004) Erythropoietin and obstructive sleep apnea. Am J Hypertens 17:783-786. doi:10.1016/j.amjhyper.2004. 04.011

78. Xu J-M, Shi G-P (2012) Emerging role of mast cells and macrophages in cardiovascular and metabolic diseases. Endocr Rev 33: 71-108. doi:10.1210/er.2011-0013

79. Yang R, Sikka G, Larson J, Watts VL, Niu X, Ellis CL, Miller KL, Camara A, Reinke C, Savransky V, Polotsky VY, O'Donnell CP, Berkowitz DE, Barouch LA (2011) Restoring leptin signaling reduces hyperlipidemia and improves vascular stiffness induced by chronic intermittent hypoxia. Am J Physiol Heart Circ Physiol 300: H1467-H1476. doi:10.1152/ajpheart.00604.2009

80. Yeo EJ, Cho YS, Kim MS, Park JW (2008) Contribution of HIF-1a or HIF-2a to erythropoietin expression: in vivo evidence based on chromatin immunoprecipitation. Ann Hematol 87:11-17. doi:10. 1007/s00277-007-0359-6

81. Yingzhong Y, Droma Y, Rili G, Kubo K (2006) Regulation of body weight by leptin, with special reference to hypoxia-induced regulation. Intern Med 45:941-946. doi:10.2169/internalmedicine.45. 1733

82. Yoon D, Pastore YD, Divoky V, Liu E, Mlodnicka AE, Rainey K, Ponka P, Semenza GL, Schumacher A, Prchal JT (2006) Hypoxiainducible factor-1 deficiency results in dysregulated erythropoiesis signaling and iron homeostasis in mouse development. J Biol Chem 281:25703-25711. doi:10.1074/jbc.M602329200

83. Yoon D, Ponka P, Prchal JT (2011) Hypoxia. 5. Hypoxia and hematopoiesis. Am J Physiol Cell Physiol 300:C1215-C1222. doi:10. 1152/ajpcell.00044.2011

84. Zanetta L, Marcus SG, Vasile J, Dobryansky M, Cohen H, Eng K, Shamamian P, Mignatti P (2000) Expression of Von Willebrand factor, an endothelial cell marker, is up-regulated by angiogenesis factors: a potential method for objective assessment of tumor angiogenesis. Int J Cancer 85:281-288

85. Zoccal DB, Simms AE, Bonagamba LGH, Braga VA, Pickering AE, Paton JFR, Machado BH (2008) Increased sympathetic outflow in juvenile rats submitted to chronic intermittent hypoxia correlates with enhanced expiratory activity. J Physiol 586:3253-3265. doi:10.1113/jphysiol.2008.154187 